\title{
Lived experiences of Iranian parents of beta-thalassemia children
}

\section{Aziz Shahraki-vahed' \\ Mohammadreza \\ Firouzkouhi' \\ Abdolghani \\ Abdollahimohammad' \\ Jamile Ghalgaie ${ }^{2}$}

'Department of Medical Surgical, Faculty of Nursing and Midwifery, Zabol University of Medical Science, Zabol, Iran; ${ }^{2}$ Emam Khomeni Hospital, Zabol University of Medical Science,

Zabol, Iran
Correspondence: Mohammadreza Firouzkouhi

Department of Medical Surgical, Faculty of Nursing and Midwifery, Zabol University of Medical Sciences, PO Box 61734-184, Ferdosi Shargi Street, Zabol, Iran

Tel +98543222 4101

Fax +98543222 3943

Email firouzkohi@gmil.com
This article was published in the following Dove Press journal:

Journal of Multidisciplinary Healthcare

29 June 2017

Number of times this article has been viewed

Introduction: Thalassemia is a chronic blood disease, which imposes adverse effects on patients and their families. Parents of such patients, given that they had the thalassemia trait, hold themselves responsible for their children's disease in addition to other difficulties, bear the burden of guilt and hopelessness and worry about the health and future of their children. This study aimed to explore the lived experiences of parents of children with thalassemia.

Methods: The present research was conducted using a descriptive phenomenological approach. A purposive sampling was carried out until data saturation. Participants included 15 parents of children with thalassemia who were referred to the Thalassemia Center of Zabol to perform therapeutic procedures for their child in 2016.

Results: Extracted interviews were analyzed employing Colaizzi's method, and four main themes were obtained, including "Gray marriage consanguinity", "Burdened with increased number of thalassemia children", "Socio-familial worries" and "Inexpressible wishes for having an ideal society".

Conclusion: The results revealed that parents of children with thalassemia experience a wide range of problems in different aspects, such as physical, emotional, mental, social, economic and familial dimensions. Their experiences are valuable and can help in achieving a better understanding of their problems, which in turn can enable the members of the treatment team to play a more active role and the society to have a better understanding of this disease.

Keywords: descriptive phenomenology, lived experiences, thalassemia major, Colaizzi's analysis approach

\section{Introduction}

Thalassemia is the most common chronic hereditary disease that is seen in almost all races globally and is transmitted from parents to children. ${ }^{1}$

Approximately 240 million of the world's population are carriers of betathalassemia, and according to the Thalassemia International Federation statistics, $\sim 200,000$ patients with thalassemia major are treated worldwide and $\sim 60,000$ patients with thalassemia major are added to this population every year. ${ }^{2}$ The prevalence rate of thalassemia is approximately $3-4 \%$ in Iran, in which there are more than three million beta-thalassemia carrier genes and approximately 800 children are born with thalassemia and added to this group annually. ${ }^{3}$ Thalassemia is a serious and life-limiting and life-threatening situation, which leads to serious disorders affecting a person's social and educational activities and is associated with feelings of inferiority and being different and creates low self-esteem in patients. ${ }^{4,5}$ 
Thalassemia is usually diagnosed when the child is a few months old. The pressure caused by having a child who requires extreme care and regular blood transfusions leads to an unsettled mental balance in parents. ${ }^{6}$

Trauma incurred to the family causes different psychological reactions in them, and family relationships are seriously affected. In a study, academic problems $(60 \%)$, problems with social interactions $(20 \%)$ and feeling of being different (24\%) and anxiety (31\%) were reported in children with thalassemia. ${ }^{7}$

These patients, like other patients with chronic and debilitating diseases, require permanent lifelong treatment and struggle with several mental health challenges, and social and economic problems, each of which somehow interferes with the principles of treatment and follow-up. ${ }^{8}$

Family members are affected by each other, and the illness of a family member directly affects the whole family. Stresses imposed on a family member will affect the entire family. Patient care undermines the energy level of family members and puts them at risk of physical, emotional and isolation consequences, and causes despair, frustration, helplessness, fear, shame and a desire to die. ${ }^{9,10}$ For this reason, these patients are also called hidden patients.

The findings of a study on families of patients with thalassemia revealed that families are faced with numerous psychological and emotional problems. ${ }^{8}$

Widayanti also believes that parents of children with thalassemia suffer and undergo pain in the process of providing daily and lifelong care. ${ }^{11}$ Moreover, parents of children with thalassemia feel anger, shock and guilt. In addition, social attitudes, stigmas and discriminations toward chronic patients, which are often rooted in inadequate information about the disease and are considered among other problems facing the families, are more harmful or more destructive than the disease itself. ${ }^{12}$ Accordingly, misconceptions and negative attitudes of parents toward their child's disease, which is often caused by lack of knowledge, could endanger their public health. Studies have shown that more parents with positive and realistic attitudes about their child's disease used tolerance mechanisms, when compared to parents with negative attitudes. ${ }^{9,10}$ The results of a research on children with thalassemia revealed that a positive attitude about life and the future of these patients increased their capacity for tolerating hardships. ${ }^{11}$

Finally, after a brief review of the results of previous studies, it was found that families of children with thalassemia are faced with psychosocial and physical problems that threaten the child, parents and other members of the family. These complications can affect the life of the children and parents in various aspects. Therefore, identifying the challenges facing parents and their children may lead to proper understanding of their individual needs and effective use of supportive and care programs. On the other hand, no qualitative study has been carried out so far to explore the experiences of the parents in Iran. In addition, there are a large number of parents having children with thalassemia in Iran, whose experiences will be useful for the rest of the world. In this regard, a question then arises as to what is the experience of having a child with thalassemia for parents like. To answer this question, the most appropriate method that can be used is the one that shows the nature of a phenomenon in its natural context along with the structure and factors affecting its formation. In this regard, among methods of research, a phenomenological study can demonstrate the nature of a phenomenon and its formation process in the natural context. A phenomenological study will enable researchers to understand the real world of everyday work and life of humans and allows them to feel the facts as they are and describe and explain human social world. Hence, researchers have sought to identify experiences of parents of children with thalassemia to emphasize the importance of the role of parents. ${ }^{13}$ In addition, this qualitative study aimed to explore the experiences of parents of children with thalassemia in the field of family, social and therapy problems. Therefore, considering the foregoing, we decided to conduct a study with the aim of exploring the experiences of parents of children with thalassemia.

\section{Methods}

Given that the present study aimed to investigate the deep and extensive experience of parents of children with thalassemia, a descriptive phenomenological approach was employed. Derived from descriptive method, a phenomenological study is based on phenomenological philosophy that focuses on understanding the essence and nature of a phenomenon. This philosophy is not concerned with only a certain part of a person; rather, it tries to understand the human responses as a whole. ${ }^{14}$

In this study, Husserl's concept of bracketing was applied. The researchers recorded their assumptions and hypothesis about the phenomenon before conducting the study so as to thoroughly understand the experience of participants.

This study was carried out in 2016 in order to understand the experience of parents of children with thalassemia in a Thalassemia Center in the city of Zabol (in the southeast of Iran). Purposive sampling was employed. In this regard, indepth and semi-structured interviews were conducted with 
12 mothers and three fathers for two to three times until data saturation. The inclusion criteria included willingness to participate in the study, mental ability of recounting experiences and having children with thalassemia. Participants were allowed to withdraw from the research process at any time. Before commencing the interview, the purpose of the research was explained, and the participants were assured about the confidentiality of their information by assigning each of them a number. After determining the location of the interview, the researchers obtained participants' permission to record their interviews. After obtaining signed inform consent from the participants, interviews were carried out using a conversational method for a duration of 60-90 min at their home. The interviews started with open questions like "Please tell us about your experiences of having a child with thalassemia" and "What challenges have you encountered in this regard?" Thereafter, the next set of questions were raised to continue and complete the interview and to access richer data based on the responses of the participants. Data collection and analysis were carried out concurrently. Interviews were recorded on a voice recorder with the consent of the participants. Each audiotape interview was listened to several times, and thereafter, verbatim transcription of interview data was carried out.

In this study, the seven-step Colaizzi method was utilized for data analysis. ${ }^{15}$ All audiotapes were listened to several times to gain close association with the content, tone and feeling. Significant words, phrases, sentences and paragraphs were extracted from each transcription. Each new item of information was compared with previously extracted items. As analysis progressed, repetitious items were retained. The data were compared, and information items were grouped into emergent theme headings - "Gray marriage consanguinity", "Increased load of problems due to increased number of children with thalassemia in the family", "Socio-familial worries" and "family's hidden wishes for having an ideal society" - in addition to emergent categories within the larger study. Data were continuously compared across and within potential thematic clusters and moved accordingly. Finally, validation of themes was approved by the participants.

The rigor of the study was assessed via credibility, dependability, confirmability and transferability strategies. ${ }^{16}$ The following measures were taken to increase the credibility of data: long-term interviews and sessions with participants, frequent reading of interviews and data drowning, utilization of complementary comments and suggestions from the partners to confirm and correct the accuracy of codes and returning the interviews to the participants after the coding process to evaluate consensus rate about the codes between researchers and participants. Dependability was confirmed by an external observer via step-by-step repetition and detailed auditing, including detailed review of findings and documents. To evaluate the research confirmability, attempts were made to present a detailed explanation about the study steps from the beginning to the end so that the external observer can do the auditing based on the documents and realize the objectivity of the study. Considering the transferability of the findings, some of the parents who had teenage children with thalassemia but did not attend the study were paid a visit, and the results were shared with them to examine the similarity between the findings obtained and their experience. The results revealed that this similarity was high.

This study was approved by the Ethical Committee of the Zabol University of Medical Sciences.

\section{Results}

Participants included 15 parents of thalassemic children and had between two and seven children. A total of 6.6, 20 and $73.4 \%$ of them had three, two and one child with thalassemia major, respectively. In addition, on average, at least one family had one child suffering from thalassemia minor.

After analyzing the interviews, four main themes were extracted, including "Gray marriage consanguinity", "Burdened with increased number of thalassemia children", "Socio-familial worries" and "Inexpressible wishes for having an ideal society".

\section{Gray marriage consanguinity}

Forced consanguineous marriage to increase the generation, birth of thalassemic children as victims of parental ignorance and parents' indifference as the leading cause of thalassemia are the constituent components of this theme.

Parents of children with thalassemia describe the marriage leading to the birth of this child as gray consanguineous marriage because they believe that it is neither bright nor black, and instead is a state between the two, where the current and future prospects of life are not seen. After the birth of children with thalassemia, parental love and other pleasures find a different shape and color. This marriage itself is responsible for the production of defective generation because parents cannot do anything to control the situation after this marriage. Births happen unconsciously. Many factors contribute to the increased number of this generation; nevertheless, parental ignorance plays the major role in this regard. They unwantedly take measures for having a healthy child, and at the meantime, a number of children are born 
with thalassemia, which creates a lot of problems for parents and decreases their life pleasures. Bad days gradually show themselves, and parents cannot do anything.

One of the participants who is a mother of two children with thalassemia describes the color of life as follows:

\section{[...] Life begins with joy and a lot of aspirations but it} change its face soon after the disease was diagnosed at birth of first child. The thalassemic child is born again among other healthy children and the happiness disappears. Our worries for the future of our thalassemic children deprive us from life pleasure and the life color changes into gray, but because there are healthy children, it is not yet black.

[...] We really didn't know how many problems are associated with the thalassemic children and gave birth to new children just like other people who are also involved in this type of marriage, but this ignorance continued until the second child was born. [Participant 6, mother of children with thalassemia]

Some participants do not see any problem with having a child with thalassemia due to the large number of children; they attributed the birth of their children with thalassemia to God's will, and believe that they will grow up among the healthy children and whatever God has ordained will happen. They also assume no responsibility toward the birth of these children.

In this regard, Participant 5, a mother of children with thalassemia, says:

[...] We did not do a single thing about contraception because we did not know our disease. Naturally the thalassemic children were born and they had no particular problems. Other children and close relatives can help us to bring them to the hospital for blood transfusion and finally they will grow up together.

\section{Burdened with increased number of thalassemia children}

Hard life with thalassemia, emotional disorganization toward children and lack of awareness of the increased burden are the constituents of this theme. The birth of a thalassemic child causes a lot of problems in the family which are divided into several categories.

Some problems are related to child care in the family, while some are related to providing care for the thalassemic child among healthy children, hospital health care problems, relationship in the society and at the school level and connections among relatives.
The conditions of the thalassemic children when compared with the healthy children increase the parental feeling of love toward those sick children in the family which creates a feeling of discrimination among the children.

This feeling of love is turned into jealousy among the other children. At the meantime, the injuries of the thalassemic child are exacerbated owing to more parental attention. Moreover, more level of care and attention given to the thalassemic child leads to psychological trauma, and parents unwittingly create new problems. All these make life harder.

Participant 6, a mother of two children with thalassemia, described these problems as follows:

[...] Life has always been really difficult when the children are born. But when you have a thalassemic child at home, imagine how difficult it is. But when the number of sick children increases, I mean thalassemic children, the number of problems you have are multiplied. You need to have this experience to understand what I'm saying.

[...] There are many problems associated with keeping healthy children besides sick ones. Some of the problems are related to parents and some to the children; Diet problems and preparing separate meals for sick children, paying attention to the special needs of these children, appearance of different skin colors and change in their facial shape, when compared with that of the healthy children, these are all problems. [Participant 8 , mother of a child with thalassemia among three other healthy children]

Participant 9, the mother of a thalassemic son, expresses her own feelings toward her son:

[...] Mothers have too much trouble, the thalassemic child needs more attention and feeling in comparison to healthy children and parents unwittingly make differences among the children, which cause jealousy and more problems among them.

\section{Socio-familial worries}

Worries related to education, job and life, and family's worries toward healthy children are the constituent elements of this theme. Having healthy and sick children in the society is considered as a worry for parents. Thalassemic children are faced with educational problems because of their disease, when compared with the healthy children. Referring to the hospital for blood transfusion and obtaining drugs on days which are their treatment's turn and the need to rest later in the home creates a gap in their education.

Moreover, as children get older, the changes occurring in their appearance make it difficult for them to be with 
healthy children in the school. Some families do not have the financial ability to bring a teacher home to compensate for the children's educational shortcomings. Most of these children with thalassemia are deprived of the opportunity of finding a good job in the society because of failure at school. Even when they reach the age of marriage, because of their specific conditions, they hardly find a healthy life partner, and a desire to marry a thalassemia spouse also creates new problems for them. These are all considered as parental worries. In the case of healthy children living with children suffering from thalassemia, healthy girls lose their chances of having a successful marriage because those who have to woo them do not choose them as their wives after seeing sick children in the family.

Participant 4, a mother of thalassemic children, expresses her worries as follows:

[...] Life is full of worries, when you have thalassemic children, the problems are multiplied. As children get older, the worries grow. In a society, in which there is no job for healthy individuals, then a patient cannot live without being supported. When they grow up, they need job, life and marriage. From now when I think about these issues, my body starts trembling. My son has suffered from many educational problems. The teachers complain that he is a slow student. I can't afford to pay for a tutor. The days when we are going to the hospital, I take leave of absence from school for my child, beforehand, but when he cannot do his homework, he is faced with some challenges and problems. Staying with healthy children is also a source of damage causing school failure.

Another participant describes problems between healthy children and sick children as follows:

[...] I've a healthy girl and two thalassemic sons. I can't think very much of the future because it scares me a lot. Right now, relatives are treating us in a special way. Until they grow up and reach the age of marriage, I pray that they can lead a healthy life and have successful marriages. If the thalassemic children survive and grow up, they still have their concerns but given that they are boys, their problems are fewer than that of girls and all of these depend on their fate.

\section{Inexpressible wishes for having an ideal society}

Promoting people's cultural viewpoints, and lack of stigma attached to the family with a sick child, good social support of sick children, achieving psychological comfort in the family and survival of sick children during their parents' lifetime are all constituent elements of this theme. Based on the views of participants during the interviews, the family of children with thalassemia wishes and hopes their wishes come true and to overcome some of their pains some day in the future. Having a sick child is associated with a lot of psychological problems for the family, and if we truly treat the essential nature of the disease, it can be seen that families do not play a crucial role in this regard because they perform the consanguineous marriage according to customs existing in the society and a sick child is born due to the their insufficient knowledge. After the diagnosis, people change their attitudes little by little. Some people show compassion, some blame and some treat patients and their families like criminals. They think that these patients are really guilty or are punished by God. They seek for ways to attach a specific stigma to the family and unwantedly cause more damages to the family. Moreover, as families are faced with special problems of keeping sick children at home and follow-up treatment and future concerns, there is no specific support in this regard, and each organization has its own job to do. Hospitals respond to patients' need today; if you could not refer to the hospital due to some problems, nobody asks why you were absent. Moreover, psychological problems are imposed on the families so that they are interwoven together. They spend days and nights with concern, and peace becomes like a mirage, achievement of which is never possible. The families hope to reach their unattainable dreams someday so that they can enjoy living together and have children, along with other members of society and hope their wishes come true.

Participant 6 tells us about her future wishes:

[...] Life is hard and sometimes you have to hear and tolerate good and bad words from other people. Thousands of good and bad words may be said behind you. Those who know you, assume a certain look, which wounds your soul. They want to say that there must be a reason why your child is sick. I always wish people raise the level of their awareness and know that these issues may happen to any other person in the society (I mean having a sick child) [...]

(Tears well up in her eyes and a lump forms in her throat, she continued) I wish there were places in the society that support us financially, provide essential services and care for the future of the children so as to reduce family problems.

Participant 10 tells us about her wishes:

[...] I hope one day we enjoy being together at the table food, sleeping and waking. I do not know why the skin 
of this child is getting darker, his face changes shape and why these scourges are happening to him. I do not want to have the anxiety of leaving for hospital. I keep waiting for the blood bag and then I see children crying and the nurses who attach blood bags to them. I always say to my husband that I wish we find peace and enjoy life someday. We can't just travel due to many restrictions, including where to go to attach the blood bags and if he feels bad, what I should do; these all are limitations.

\section{Discussion}

Using a phenomenological and a familial-centered approach, we addressed the gap in the existing literature by providing a unique and detailed insight into the experiences of parents of children with thalassemia major. We identified four core themes: "Gray marriage consanguinity", "Burdened with increased number of thalassemia children in the family", "Socio-familial worries" and "Inexpressible wishes for having an ideal society". These findings highlighted the dynamic nature of parent's experiences as they vacillate between different feelings of having children with thalassemia and how to overcome social and health problems.

Changes made in the color of life due to the birth of children with thalassemia is a phenomenon affecting love and affection between parents, and pleasures of life become less evident. Gray is a description offered by the parents due to a change and the emergence of the shadow of sadness in life, which makes the future to look uncertain. Consanguineous marriage and its consequences emerging in the form of children born with thalassemia are the factors leading to this situation. ${ }^{17}$ Moreover, lack of awareness regarding the consanguineous marriage causes increased occurrence of genetic defects such as thalassemia. ${ }^{18}$ Parents hold various viewpoints according to communities in which they live. The above results are also seen in similar studies. ${ }^{19,20}$ The birth of children with genetic disabilities imposes a lot of problems on the quality of parental life in terms of support, treatment, social acceptance and parental relationships, which subsequently causes a lot of psychological problems for the parents. Consequently, life is not enjoyable for parents, and parents' views on life will change. There is also a high correlation between consanguineous marriage and the genetic anomaly. Parents' ignorance plays a major role in the development of thalassemia; nevertheless, parents state medical reasons as the main cause of such disease and do not believe in genetics. Several other studies have also shown that children with disabilities cause psychological disorders for parents and affect their perspective toward life. ${ }^{20,21}$

Another finding of the present study was that the birth of a new thalassemic child creates more problems for the families. Consequently, life gets harder for parents. Many of these problems are related to parents' lack of awareness because they give birth to new children regardless of the conditions of life. ${ }^{22}$ In this study, families which were studied belong to middle class in terms of economic status, and when children are born, the disease-related burden increases. These cases cannot be seen in all societies, and their frequency varies depending on the conditions of different societies. Genetic hemoglobin disorders like thalassemia increase the burden of parental problems because they impose disabilities for patients in the future, and these problems are different in less developed, developing and developed countries. In a qualitative study on children with thalassemia in Pakistan, high volume of family's problems have been reported, and the researchers believe that some families cannot afford the cost of transporting the child to the hospital for routine treatment procedures. ${ }^{23}$ Even some families living in the village undergo much more problems in comparison with those living in cities, and the problems are multiplied with increase in the number of children. ${ }^{24,25}$ Other studies have also demonstrated that parents of disabled children with chronic health problems are suffering from many problems because of the poor quality of life and psychological conflicts, anxiety and depression. Educational, employment and marriage worries, and family's worries toward the healthy children known as interfamilial and social worries are the other findings of the present study, which reveal that as thalassemia children are born, families face particular worries, which are manifested in the children's development process in various ways. ${ }^{26}$

Parents' major worries are divided into the following levels: family level which includes child care and communication between healthy and sick children; society level which includes development of patients in the society and their new educational lives. ${ }^{27}$ In a study, thalassemia is introduced as a life-threatening disease affecting family members and their activities, thus affecting the management of life and children. Furthermore, thalassemia imposes stresses on the quality of life and health of children and parents because of its severity, treatment burden and long care process, and high levels of parental responsibilities toward children in society and their evolution process.

Thalassemic children suffer from physiological, psychological, social and spiritual problems because of the long 
treatment protocols disrupting school and social activities. Nevertheless, most parents are not skilled enough in this issue; their concerns increase and their lives will be affected, which is in line with the results of the present study. In addition, thalassemia children who are treated will suffer from complications like pale skin and changes in face and body appearance, and therefore, they cannot work like normal children.

Moreover, the disease causes despair, lack of social acceptance and intellectual and mental problems in the child. It also imposes psychological, social and economic pressures on the family, which eventually leads to the state of hopelessness about the future, psychological reactions and impaired social interactions. Therefore, this complex situation heavily affects the family. In addition, the psychosocial aspects of the life of thalassemic adults cause various difficulties and challenges for parents because of many problems, such as education, sport activity, body image, social life, disease complications and medical and financial support. Moreover, their major challenges include physical, emotional and cognitive problems and challenges caused by impaired quality of life. If these challenges are taken into consideration, psychological pressure imposed on the parents can be reduced, and achievement levels of people with thalassemia will increase. ${ }^{28}$

Another result of the present study was family's wish of an ideal society for people living with thalassemia. Families of children living with thalassemia have their own wishes, such as promotion of the people's viewpoints, not attaching stigma to the family with a sick child, good social support of sick children and psychological comfort to the family so that the difficulty of having a sick child is facilitated and they are given the chance to have a pretty good life.

The results of a study on Egyptian's cultural views toward thalassemia showed that the cultural views play a major role in the management and therapeutic care for thalassemic children and the Egyptian's cultural views differ from those of patients living in Western countries. Cultural views, availability of financial resources and access to medical facilities are important in the management of thalassemia disease, and if cultural views are improved, we can achieve a better awareness of the thalassemia disease in order to take appropriate contraceptive measures and facilitate treatment of children with thalassemia. ${ }^{29}$

Moreover, the results of a study introduced thalassemia disease as a serious health disorder, which is associated with enormous physical and psychosocial problems. These problems not only reduce the life expectancy of patients but also deprive them of the right to enjoy a good life. Therefore, they need health and social support systems which can give them hope in their lives. Their desire is to achieve a relatively good condition to live a better life. ${ }^{30}$

Due to a lack of awareness toward thalassemia in Malaysia, patients are faced with many problems like stigmatization, which affects their life. Another study referred to thalassemia patients' and caregivers' social problems as causing psychosomatic disorders and reducing their quality of life. One of these problems was stigmatization of patients that causes fear and anxiety in patients in the society. Moreover, the needs of thalassemia children, which are effective in the treatment process, are also mentioned. Appropriate medical management, psychosocial interventions and effective family support are considered as wishes for the future of the children with thalassemia. There were no views contradicting the results of the present study. ${ }^{31-33}$

The results of previous studies on thalassemic children and other similar genetic disorders indicate that the consanguineous marriages are more prevalent among people in certain societies, most of which belong to developed and less developed countries. These people are faced with varying degrees of social and economic problems and have certain views about consanguineous marriage. Their problems differ depending on their education level, economic status, place of residence and access to treatment facilities and other factors. When these people migrate and settle in developed countries, their problems are decreased, which is indicative of better living conditions in new places. According to considerable challenges facing the parents of children with thalassemia, authorities and health and social systems should give more attention to them so that they can cope with unwanted situations and provide necessary treatment measures for their sick children. Nevertheless, these problems differ in various countries, but the problems are the same. Themes obtained in the present study were extracted from experiences of a limited number of participants; therefore, it is difficult to generalize them to other societies. However, these findings can be valuable for the managers of treatment and support organizations in the planning process.

One of the positive aspects of this study was the equal socioeconomic level of parents, which is indicative of the same type of problems. The negative aspect of this study was that parents refused to talk about painful aspects of their lives, which was a result of the difficulties encountered throughout their life. 


\section{Conclusion}

The results demonstrated multiple experiences of parents of children with thalassemia. According to the results, it is important to give emphasis on different aspects such as providing appropriate health services, raising parents' level of awareness in the field of contraception and manner of providing care for the sick children in the family, implementing periodic training programs for other family members and close relatives of patients, establishing private institutions with the participation of the public sector without imposing any economic cost on families, improving the psychological state of the families and continuation of the marriage life, raising public awareness toward thalassemia via media programs and satisfying the obvious and hidden needs of families so that relative appropriate conditions are provided for the families.

\section{Acknowledgments}

This study was financed by the Zabol University of Medical Sciences. The authors wish to thank all the participants of the study for sharing their experience with the researchers, and acknowledge that without the participants' cooperation, this research could not have been accomplished.

\section{Author contributions}

The preliminary research design, data collection and analysis and drafting of the manuscript were done by AS and JG under the supervision of MF. Critical revisions of the manuscript for important intellectual content and supervision were the responsibility of $\mathrm{MF}$ and $\mathrm{AA}$ who also contributed to the design and the final shape of the manuscript. All authors contributed toward data analysis, drafting and critically revising the paper and agree to be accountable for all aspects of the work.

\section{Disclosure}

The authors report no conflicts of interest in this work.

\section{References}

1. Jain M, Bagul AS, Porwal A. Psychosocial problems in thalassemic adolescents and young adults. Chron Young Sci. 2013;4(1):21-23.

2. Bala J, Sarin J. Empowering parents of children with thalassemia. Int J Nurs Care. 2014;2(1):22-25.

3. Pouraboli B, Abedi H, Abbaszadeh A, Kazemi M. Silent screams: experiences of caregiver suffering by parents of children with thalassemia: a qualitative study. J Qual Res Health Sci. 2014;3(3):281-291.

4. Caocci G, Efficace F, Ciotti F, et al. Health related quality of life in Middle Eastern children with beta-thalassemia. BMC Blood Disord. 2012;12(1):1-7.

5. Yahia S, El-Hadidy MA, El-Gilany AH, Anwar R, Darwish A, Mansour AK. Predictors of anxiety and depression in Egyptian thalassemic patients: a single center study. Int J Hematol. 2013;97(5):604-609.
6. Imani E, Asadi Nooghabi F, Hosseini Teshnizi S, Yosefi P, Salari F. Comparison quality of life in patients with thalassemia major based on participating in group activities, Bandar Abbas. Sci J Iran Blood Transfus Org. 2013;10(2):198-206.

7. Ismail A, Campbell MJ, Ibrahim HM, Jones GL. Health related quality of life in Malaysian children with thalassaemia. Health Qual Life Outcomes. 2006;4(39):1-8.

8. Roy T, Chatterjee SC. The experiences of adolescents with thalassemia in West Bengal, India. Qual Health Res. 2007;17(1): 85-93.

9. Sawatzky JE, Fowler-Kerry S. Impact of caregiving: listening to the voice of informal caregivers. J Psychiatr Ment Health Nurs. 2003;10(3):277-286

10. Mashayekhi F, Jozdani RH, Chamak MN, Mehni S. Caregiver burden and social support in mothers with $\beta$-thalassemia children. Glob $J$ Health Sci. 2016;8(12):206-212.

11. Widayanti CG. The perceived role of god in health and illness: the experience of javanese mothers caring for a child with thalassemia. Jurnal Psikologi Undip. 2011;9(1):50-56.

12. Baghianimoghadam MH, Sharifirad G, Rahaei Z, Baghianimoghadam B, Heshmati $\mathrm{H}$. Health related quality of life in children with thalassaemia assessed on the basis of SF-20 questionnaire in Yazd, Iran: a case-control study. Cent Eur J Public Health. 2011;19(3):165-169.

13. Wu M, Hsu L, Zhang B, Shen N, Lu H, Li S. The experiences of cancer-related fatigue among Chinese children with leukaemia: a phenomenological study. Int J Nurs Stud. 2010;47(1):9-59.

14. Grove SK, Burns N, Gray JR. Understanding Nursing Research: Building an Evidence-Based Practice. Philadelphia:Elsevier Health Sciences; 2014.

15. Edward KL, Welch T. The extension of Colaizzi's method of phenomenological enquiry. Contemp Nurse. 2011;39(2):163-171.

16. Thomas E, Magilvy JK. Qualitative rigor or research validity in qualitative research. J Spec Pediatr Nurs. 2011;16(2):151-155.

17. Lingen M, Albers L, Borchers M, et al. Obtaining a genetic diagnosis in a child with disability: impact on parental quality of life. Clin Genet. 2016;89(2):258-266.

18. Bener A, Hussain R, Teebi AS. Consanguineous marriages and their effects on common adult diseases: studies from an endogamous population. Med Princ Pract. 2007;16(4):262-267.

19. Darr A, Small N, Ahmad WI, Atkin K, Corry P, Modell B. Addressing key issues in the consanguinity-related risk of autosomal recessive disorders in consanguineous communities: lessons from a qualitative study of British Pakistanis. J Community Genet. 2016;7(1):65-79.

20. Amber E, Maurice-Stam H, Boelen CC, et al. Parenting a child with phenylketonuria or galactosemia: implications for health-related quality of life. J Inherit Metab Dis. 2011;34(2):391-398.

21. Quine L, Pahl J. First diagnosis of severe mental handicap: characteristics of unsatisfactory encounters between doctors and parents. Soc Sci Med. 1986;22(1):53-62.

22. Piel FB. The present and future global burden of the inherited disorders of hemoglobin. Hematol Oncol Clin North Am. 2016;30(2):327-341.

23. Towell T, Cartwright T. Pakistani children's experiences of growing up with beta-thalassemia major. Qual Health Res. 2015;25(3):386-396.

24. Ones K, Yilmaz E, Cetinkaya B, Caglar N. Assessment of the quality of life of mothers of children with cerebral palsy (primary caregivers). Neurorehabil Neural Repair. 2005;19(3):232-237.

25. Sajedi F, Alizad V, Malekkhosravi G, Karimlou M, Vameghi R. Depression in mothers of children with cerebral palsy and its relation to severity and type of cerebral palsy. Acta Med Iran. 2010;48(4):250-254.

26. Wacharasin C, Phaktoop M, Sananreangsak S. Examining the usefulness of a Family Empowerment Program guided by the Illness Beliefs Model for families caring for a child with thalassemia. J Fam Nurs. 2015;21(2):295-321.

27. Ishfaq K, Ali AA, Hashmi M. Mothers' awareness and experiences of having a thalassemic child: a qualitative approach. PJSS. 2015;35(1):109-121.

28. Khurana A, Katyal S, Marwaha RK. Psychosocial burden in thalassemia. Indian J Pediatr. 2006;73(10):877-880.

29. Adly AA, Ebeid FS. Cultural preferences and limited public resources influence the spectrum of thalassemia in Egypt. $J$ Pediatr Hematol Oncol. 2015;37(4):281-284. 
30. Wong LP, George E, Tan JA. A holistic approach to education programs in thalassemia for a multi-ethnic population: consideration of perspectives, attitudes, and perceived needs. J Community Genet. 2011;2(2):71-79.

31. Shaligram D, Girimaji SC, Chaturvedi SK. Psychological problems and quality of life in children with thalassemia. Indian J Pediatr. 2007;74(8): 727-730.
32. Haghpanah S, Nasirabadi S, Ghaffarpasand F, et al. Quality of life among Iranian patients with beta-thalassemia major using the SF-36 questionnaire. Sao Paulo Med J. 2013;131(3):166-172.

33. Tsiantis J, Xypolita-Tsantili D, Papadakou-Lagoyianni S. Family reactions and their management in a parents group with beta-thalassaemia. Arch Dis Child. 1982;57(11):860-863.

\section{Publish your work in this journal}

The Journal of Multidisciplinary Healthcare is an international, peerreviewed open-access journal that aims to represent and publish research in healthcare areas delivered by practitioners of different disciplines. This includes studies and reviews conducted by multidisciplinary teams as well as research which evaluates the results or conduct of such teams or health care processes in general. The journal covers a very wide range of areas and welcomes submissions from practitioners at all levels, from all over the world The manuscript management system is completely online and includes a very quick and fair peer-review system. Visit http://www.dovepress.com/ testimonials.php to read real quotes from published authors.

Submit your manuscript here: https://www.dovepress.com/journal-of-multidisciplinary-healthcare-journal 